\title{
Cross-laminated Timber Design by Flattened Bamboo based on Near-infrared Spectroscopy and Finite Element Analysis
}

\author{
Chao Li,* Lixin Zhang, Xinyu Ma, and Xilong Wang \\ Bamboo-wood composite cross-laminated timber (BCLT) is a new kind of \\ wood structure material. Studies of the mechanical properties of BCLT \\ have the potential to improve its utilization. Compared with the traditional \\ testing method, this paper designs a fast and effective nondestructive \\ testing method. Three types of composite BCLT plates were designed and \\ made. Multi-point sampling of unit-converted timber was done using a $900-$ \\ $1700 \mathrm{~nm}$ NIR spectrometer. Mechanical properties of the unit converted \\ timber were obtained through a four-point bending experiment. The data \\ set consisted of near-infrared spectrum data and mechanical property data. \\ The NIR prediction model was obtained by partial least squares method. \\ The coefficients of determination for the density, MOR and MOE prediction \\ models were $0.88,0.88$, and 0.85 , respectively. Finally, the finite element \\ modeling analysis of BCLT plate was carried out according to the element \\ material prediction model, and the prediction of mechanical properties of \\ BCLT plate was achieved. For the three BCLT plates, the prediction error \\ of the finite element model was less than $10 \%$, showing that the finite \\ element analysis method is feasible to predict the mechanical properties \\ of BCLT plate.
}

Keywords: Bamboo and wood composite; Cross-laminated timber; Four-point bending experiment; Finite element analysis; Near-infrared spectroscopy

Contact information: Northeast Forestry University, Harbin, 150040, China;

* Corresponding author: lichaonefuzyz@nefu.edu.cn

\section{INTRODUCTION}

Cross-timber (CLT) is a solid wooden board made of timber or structural composite sheets with an orthogonal $\left(90^{\circ}\right)$ arrangement. It is a kind of prefabricated engineering wood product made using structural adhesive (Mohammad et al. 2018). This orthogonal structure makes CLT material have good dimensional stability. In addition, CLT has excellent fire resistance. In the combustion process, a carbonization layer will be generated to block the entry of air, thus further slowing down wood combustion, ensuring that CLT can maintain a certain structural stability and provide escape time. In Japan, the seismic performance of an 8-story wood CLT building was studied on the vibration table of a laboratory. The experimental results showed that CLT has good seismic performance. As a new green building material, CLT can be widely used in the wall panel, floor panel, and roof panel of buildings, as well as the main structure or bridge panel of bridges. As a building material, it is necessary to explore its mechanical properties.

Bamboo is the fastest growing and most widely used plant on earth. It is a rich and sustainable resource. Bamboo forests account for about $1 \%$ of the world's total forest area. There are 31.5 million hectares of bamboo forests in the world, $60 \%$ of which are concentrated in fast-growing countries such as China, India, and Brazil (Sharma et al. 
2015). Bamboo has rich resources, excellent materials, and fast growth. It has significant economic, ecological, and social benefits. It can be used as construction material instead of wood. Its physical and mechanical properties are good, with small water absorption coefficient, low expansion rate, lack of cracking, little deformation, and other advantages. Bamboo has been used in architecture since ancient times. During the long development of primitive bamboo architecture, unique bamboo architecture has gradually formed in many parts of the world (Hong et al. 2019). By evaluating the performance of bamboo, Huang et al. (2017) compared the model of bamboo unit with that of wood unit. The experiment showed that the application effect of bamboo in light buildings was better than that of wood. Setiyowati and Mappaturi (2020) adopted the content analysis method to compare the natural treatment of bamboo with chemical treatment, and they developed a good bamboo treatment method, which can be applied to bamboo buildings. With the increase of demand for wood resources and the decrease of supply, it is attempted to combine bamboo and wood for CLT manufacturing - BCLT. In this way, it may be possible not only to make full use of the mechanical advantages of wood and bamboo, but also to alleviate the current situation of tight wood demand (Sun et al. 2020), realize the reasonable allocation of bamboo and wood resources, generate economic and ecological benefits, and promote the development of green buildings.

Many scholars have done related studies on the mechanical properties of CLT. Pang and Jeong (2019) considered the influence of different wood varieties, thickness, slab composition, and cross-depth ratio on the flexural strength and stiffness of CLT, and the experiment showed that larch with higher density had higher load-resisting capacity on the span length. Sun et al. (2020) tested the bending and shear properties of hemlock orthogonal gluewood with five layers of plate structure in the strong and weak axis direction and analyzed the mechanical properties of CLT plate in the two axis directions. The flexural elastic modulus in the strong axis direction was higher. Corpataux et al. (2020) used tropical fast-growing materials to make new CLT plates and measured the mechanical strength of the new type of plates, thus providing a new method for the composition of CLT plates. Bellini et al. (2020) glued steel nails on the CLT shear surface to enhance the mechanical properties of CLT. The experiment showed that the mechanical properties of CLT composite materials composed of this method were required. Cao et al. (2020) studied the mixed structure connected by mixed soil and CLT, studied its mechanical properties through destructive experiments, and established a lag model based on the experimental data. The prediction results of the model were in good agreement with the experimental results, which can provide a good database for the finite element analysis of composite materials. Gao et al. (2015) used ABAQUS finite element analysis software to simulate the mechanical properties of CLT, and the relative errors between the predicted and measured values of the failure loads in different directions of the 3-layer CLT were $+7.04 \%,+3.96 \%$, and $-2.54 \%$. There was a relative error between the finite element simulation value and the measured value, but the difference was not big, which indicates that the finite element modeling to simulate the mechanical property of CLT is feasible. In the analysis and prediction of mechanical properties of materials, many scholars have also adopted the method of near-infrared spectroscopy. Li et al. (2010) used near infrared spectrum combined with nonlinear partial least square method to accurately predict larch density. Jiang et al. (2006) studied the NIR spectra collected from three sections of Chinese fir, and finally predicted the density of the sections. Yang et al. (2016) established a partial least squares model to predict cellulose, xylan, and lignin in bamboo components, and the model 
coefficients of determination reached $0.994,0.990$, and 0.996, which could distinguish different parts of bamboo well.

In this paper, three combined BCLT boards were designed and made. They were: bamboo-wood-bamboo sample (BWBCLT), wood-bamboo-wood sample (WBWCLT), and composite bamboo-wood-bamboo sample (CBWBCLT). The mechanical properties of the three kinds of BCLT plates were tested, and the results showed that the hemlock layer was damaged by shear, bamboo was basically intact, and CBWBCLT samples had the best mechanical properties. Because BCLT plate is a kind of composite material, it is impossible to directly analyze its overall mechanical properties by using near-infrared spectrum data. So the finite element method is introduced. According to the near-infrared spectral data and mechanical property data of a single plate, a partial least square method was used to establish the near-infrared prediction model, and finite element modeling analysis was carried out for BCLT plate according to the prediction model. The finite element modeling analysis of BCLT plate was carried out according to the prediction model, allowing prediction of the mechanical properties of the BCLT plate. In this paper, near-infrared spectroscopy was combined with finite element analysis to design a BCLT combination with good mechanical properties and presented a method for nondestructive testing of the mechanical properties of BCLT composite plates.

\section{MATERIALS AND METHODS}

\section{Materials}

Flattened bamboo and hemlock were used for the timber unit of bamboo-wood composite CLT. Six-year-old bamboo was obtained from Chongyi County, Jiangxi Province, which was $1280 \mathrm{~mm}$ long, $135 \mathrm{~mm}$ wide, and $8 \mathrm{~mm}$ thick. Its moisture content was $6.56 \%$ and its density was $0.617 \mathrm{~g} / \mathrm{cm}^{3}$. Bamboo has excellent physical properties and is not susceptible to deformation and cracking, but its diameter is small. The traditional processing technology has some shortcomings, so that its utilization ratio is low. In this experiment, the bamboo was treated by softening and flattening, as shown in Fig. 1, after first slitting the bamboo tube and softening it by exposure to high temperature. Softening increases the expansion slot of the bamboo slips and gives them a temporary plasticity. Then the bamboo slips are unfolded into flat bamboo pieces under the action of mechanical pressure. In contrast to the traditional flat-half bamboo spreading method, one can obtain pieces of bamboo that have double the width. Flattened bamboo has a higher hardness, such that it is not suitable for direct longitudinal cutting by machine (Atienza et al. 2020). In the present work, a planer was used to plane the flat bamboo. After planning, it was sanded again until the thickness became $6 \mathrm{~mm}$, as shown in Fig. 2(a). The average tensile strength and compressive strength of bamboo slices were 107.4 and $81.6 \mathrm{MPa}$, respectively.

The wood used in the experiment was Canadian hemlock, which has moderate hardness, high bending strength, and good durability. Hemlock is the original plate with a dry density of $0.47 \mathrm{~g} / \mathrm{cm}^{3}$ and an average moisture content of $15 \%$. Figure 2(b) shows a smooth hemlock sawn timber with a cutting machine cut to $1280 \mathrm{~mm}$ long and $20 \mathrm{~mm}$ thick on both sides. 


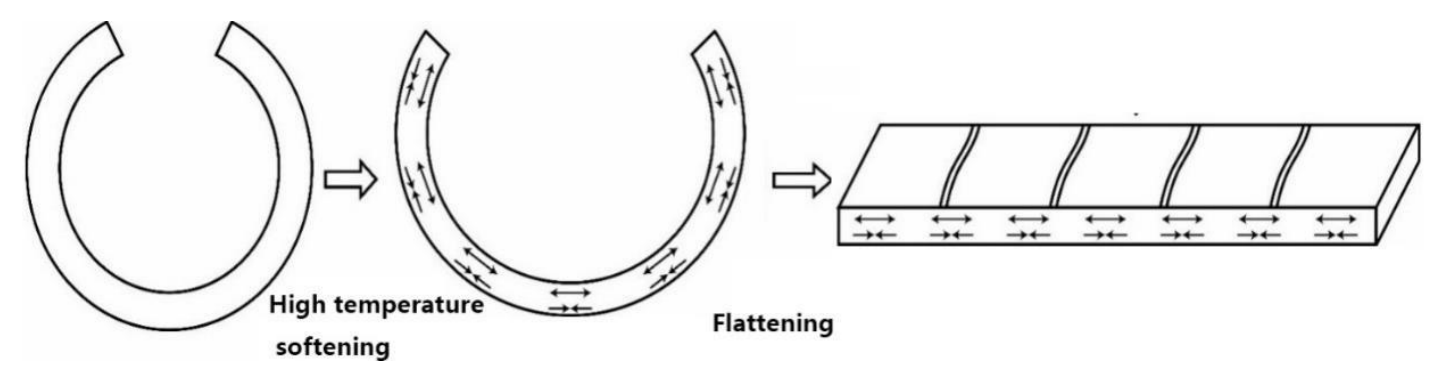

Fig. 1. Flattening process of bamboo tube

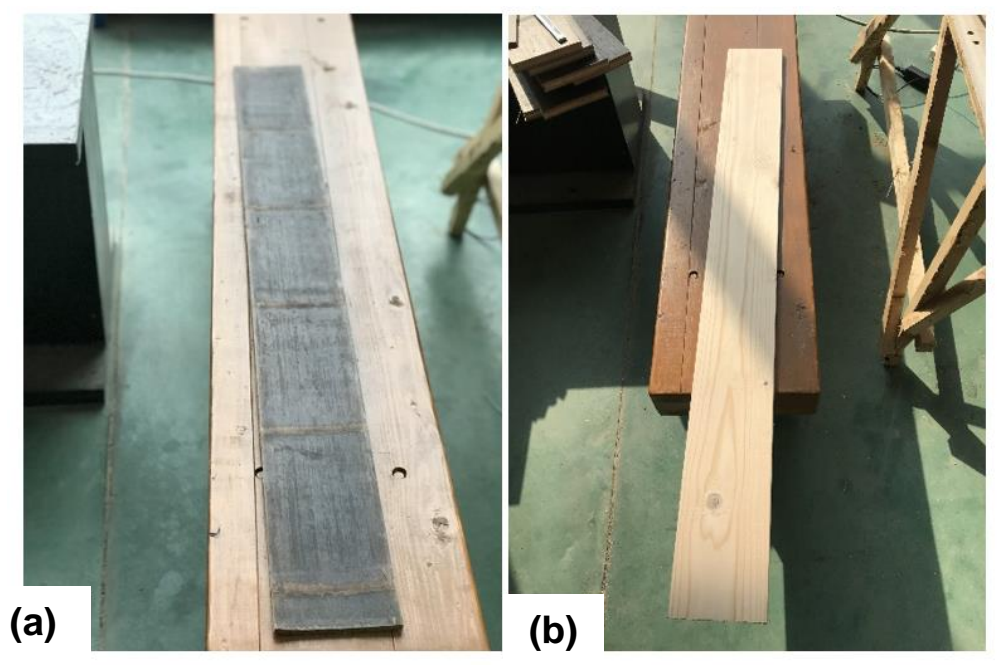

Fig. 2. CLT timber unit (a) Flat bamboo plank; (b) Hemlock plank

\section{Experimental Procedure for Single Plate}

Obtain near infrared spectrum data

A single spectrograph was used in the experiment. The optical fiber probe had a diameter of about 5 millimeters on the spectrometer. The wavelength range was $900 \mathrm{~nm}$ to $1700 \mathrm{~nm}$ with a resolution of $3.0 \mathrm{~nm}$. The NIR measurement was carried out as shown in Fig. 3. The light from the light source enters into the sample and is reflected, refracted, diffracted, and absorbed back to the sample surface (Amusant et al. 2016). NIR radiation diffuses after carrying information about the internal structure of the sample. Thereby, the NIR diffuse reflectance can be used to detect information about powder, fiber, and other samples without requiring initial chemical treatment.

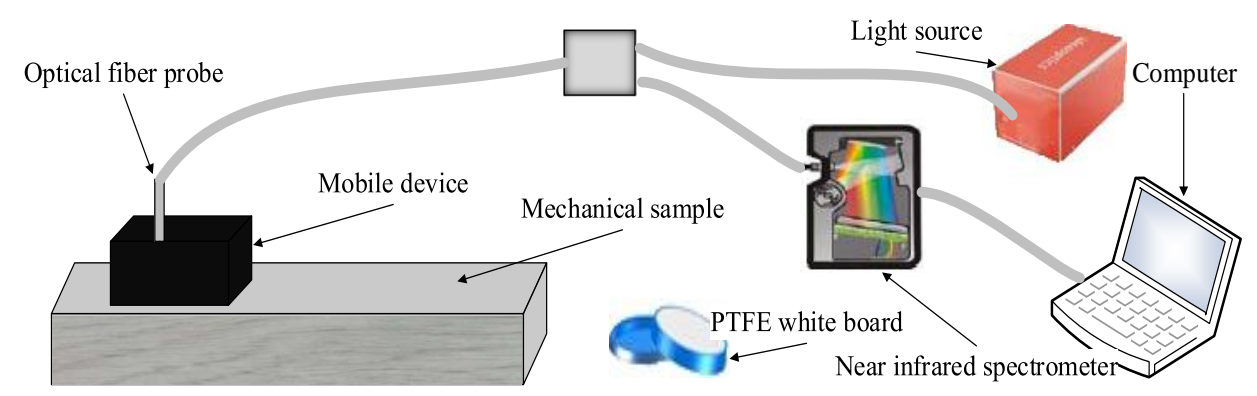

Fig. 3. NIR measurement process; PTFE - polytetrafluoroethylene 
SPEC View 7.1 was used to collect and record spectra. The sampling method is shown in Fig. 4. Each scanning point was scanned 30 times and averaged into a single spectrum. For each sample, eight longitudinal spectra and eight longitudinal spectra of the tangential surface of the sample were averaged into one spectrum (Mo et al. 2020). According to the visual image information, it was possible to obtain the position, size, length, and other geometric forms of the plate calibration coordinates and to establish the geometric region model of the plate under the geometric coordinates.

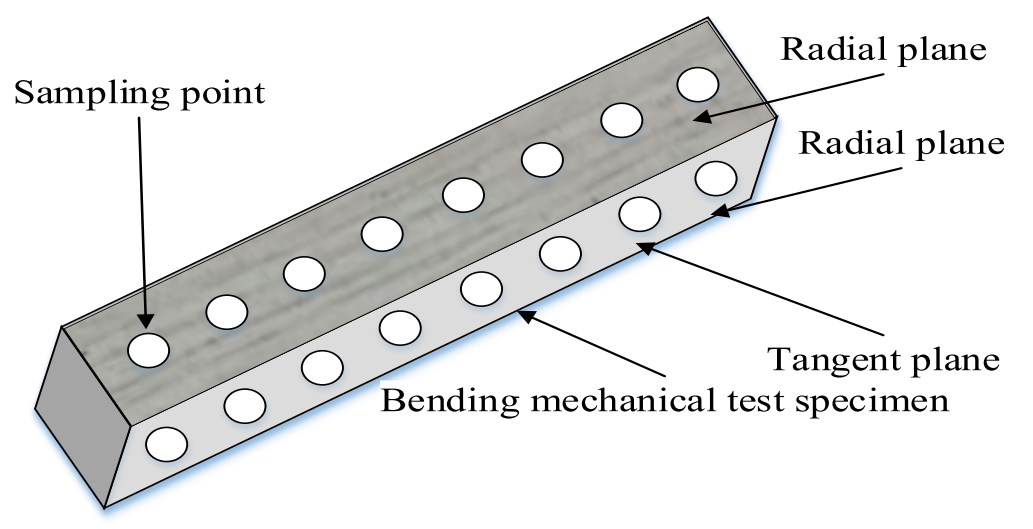

Fig. 4. Sampling points for each specimen

\section{Specimens bending experiment}

The four-point bending test method was used for flexural evaluation. The electronic universal mechanical testing machine was used. The experiment used a $50 \mathrm{KN}$ load cell to record the load during the test. The loading controller loaded the sample at a loading speed of $10 \mathrm{~mm} / \mathrm{min}$ until the sample was damaged and failed, recorded load-displacement data, and calculated the bending modulus and static bending strength of the single plate (Babiak et al. 2018).

After the bending test, the MOE and MOR were measured, as shown in Fig. 5. According to GB/T 17657 (2013), Equations 1 and 2 were used to calculate the bending modulus and static bending strength of the sample (Tiryaki and Hamzaçebi 2014),

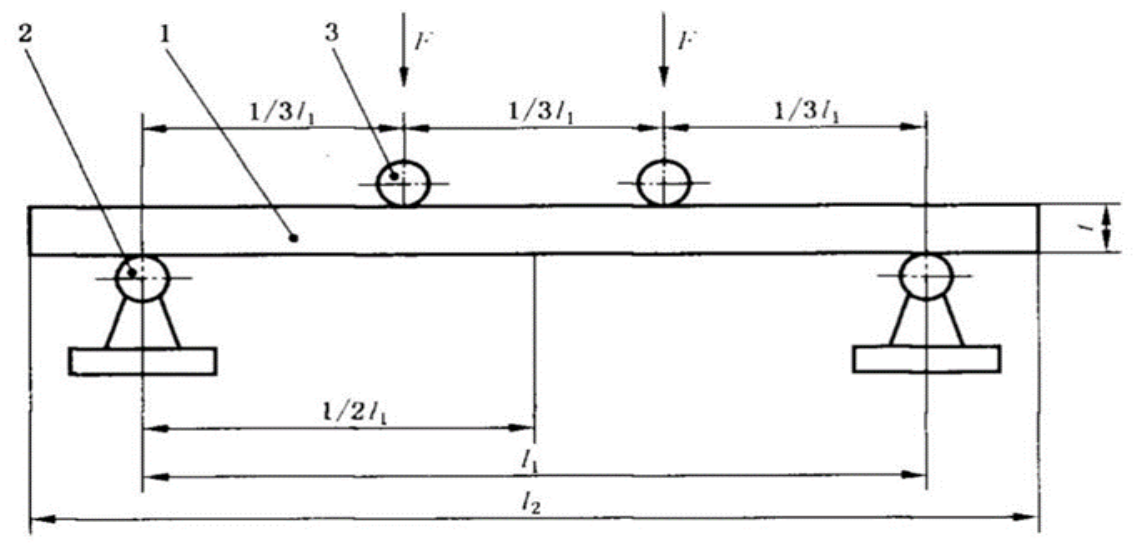

Fig. 5. Four-point bending standard: sample (1), support roll (2), and load roll (3); $t$ is the thickness $(\mathrm{mm})$ of the sample, and $F$ is the load $(\mathrm{N})$ 


$$
\begin{aligned}
\text { MOE } & =23 \Delta P l^{3} / 108 b t^{3} \Delta y \\
\text { MOR } & =F_{\text {max }} l / b t^{2}
\end{aligned}
$$

where $\Delta P$ is the load increment before the tested samples reach their elastic limit $(\mathrm{N}), \Delta y$ is the deflection at the mid-span cross-section $(\mathrm{mm}), F_{\max }$ represents the maximum load in the whole bending test process $(\mathrm{N}), l$ is the distance between two supports, and $b$ and $t$ are the width $(\mathrm{mm})$ and the height $(\mathrm{mm})$ of the tested samples, respectively.

\section{NIR spectroscopy pretreatment}

Noise is included in the NIR spectral data, which is not conducive to the further analysis and processing of signals (Yu et al. 2017). In order to obtain the spectral data with high signal to noise ratio and low interference during the establishment of the prediction model, spectral preprocessing is required. The Savitzky-Golay smooth filter was used to preprocess the spectral data, which is a common spectral processing method and widely used in spectral analysis. As shown in Fig. 6, this method employs $k$ order polynomial fitting the length of a data point in the window, and then obtaining the fitting result after discretization. The S-G filter is actually a moving window weighted average algorithm, but its weighting coefficient is not a simple constant window, but it acts as a sliding window given in high order polynomial least squares fitting. The effect of S-G filtering changes depending on the choice of window width that can meet the needs of a variety of occasions.

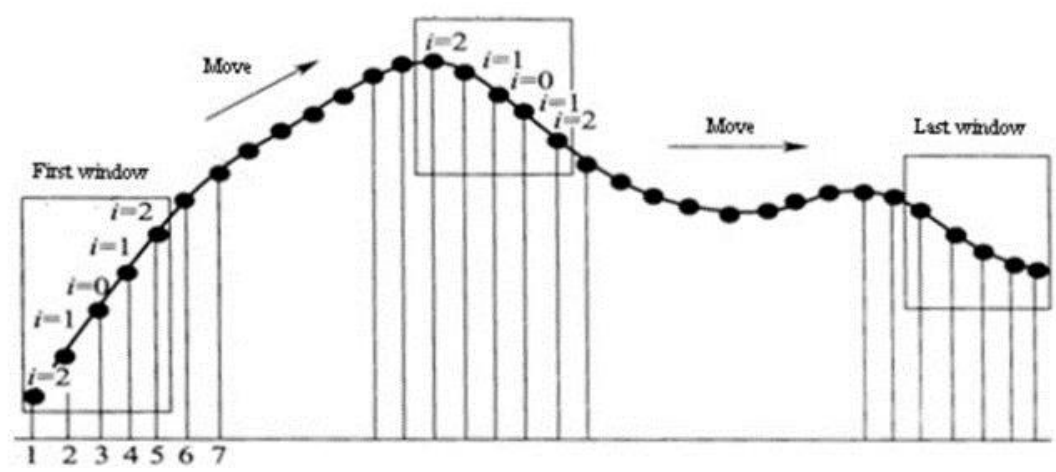

Fig. 6. Window movement smoothing diagram

\section{Sample optimization}

The binary K-means algorithm was used to remove the abnormal samples, divide all samples into a cluster, then divide the cluster into two parts, and then select the cluster that can minimize the clustering cost function to two parts (Yu et al. 2018). This was continued until the number of clusters was equal to the number given by the user $k$, trying to make the distance between each category larger, making the distance between subclasses smaller, and removing the abnormal samples. The use of the binary K-means algorithm can effectively improve the calculation efficiency.

The specific algorithm is as follows: the input of the algorithm is the NIR spectrum data set (Y), the threshold of intra-group similarity and the threshold of inter-group similarity. First, the binary K-means algorithm is run on the near-infrared spectrum data set to obtain $\mathrm{C} 1$ and $\mathrm{C} 2$. Secondly, if the similarity of $\mathrm{C} 1$ or $\mathrm{C} 2$ is greater than the fitting criterion, a binary $\mathrm{K}$-means algorithm is run on $\mathrm{C} 1$ or $\mathrm{C} 2$ to divide it into two groups, and 
then the second step is repeated for the two groups. Thirdly, if the similarity within all groups is less than the fitting intensity, the similarity is calculated within the group, and combine the groups with the similarity less than the fitting intensity threshold. For each merging of two subgroups, the number of original categories is reduced by one until only two categories remain. The output of the algorithm is the clustering result. Samples larger than the in-group threshold are removed by the process.

\section{Modeling}

Spectral data modeling is the most important step, which uses principal component analysis (PCA) and partial least squares (PLS). Partial least square method can simplify data structure in modeling, making it possible to observe the characteristics of multidimensional data on a two-dimensional plane. Through the least squares analysis, one can obtain a regression model with multiple dependent variables and multiple independent variables. The correlation can be observed directly between two sets of variables on the plane. Similar structure points can be observed between samples, which can enrich the content of data system analysis.

\section{Experimental Procedure for BCLT}

Prepare BCLT sheet

The design process of BCLT board is shown in Fig. 7.
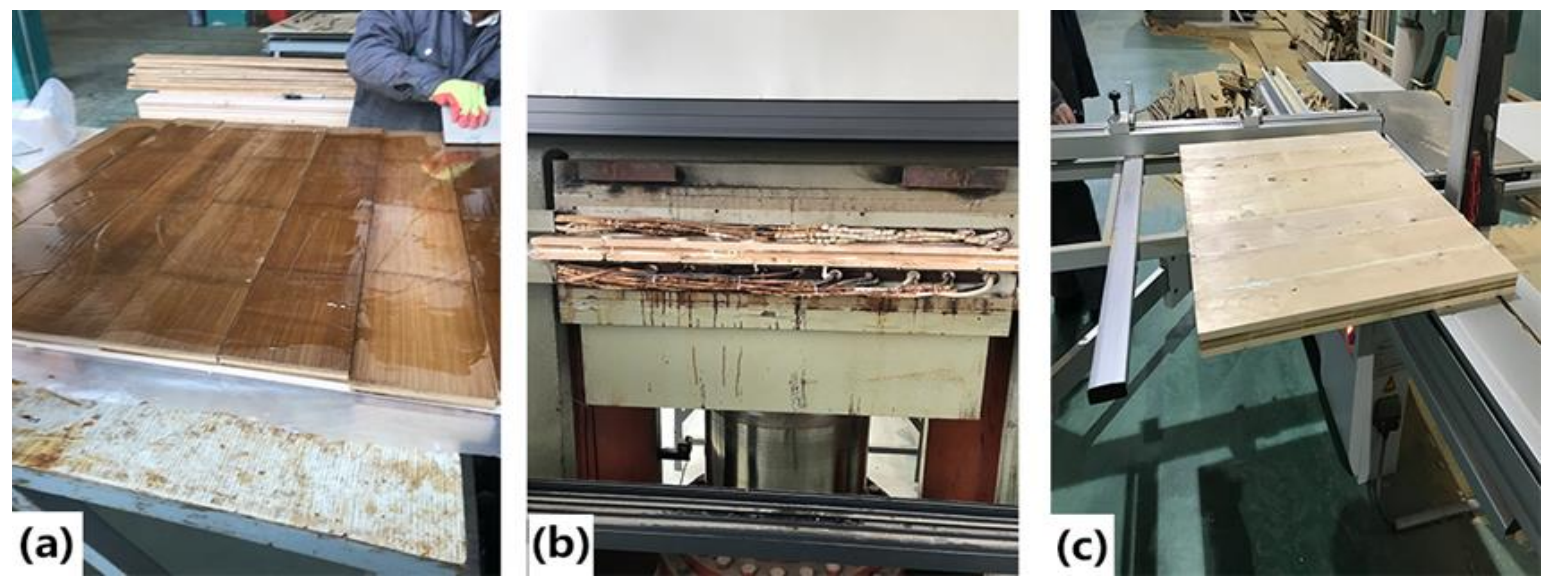

Fig. 7. Process of making BCLT board: (a) sizing, (b) pressure, and (c) cutting into boards

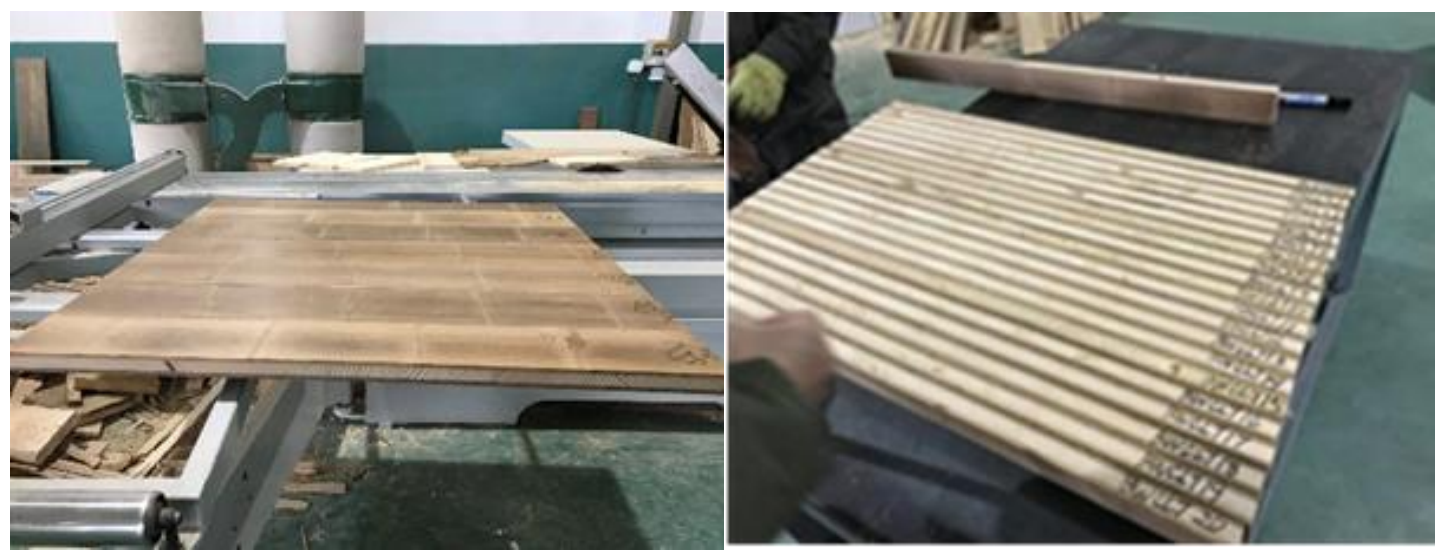

Fig. 8. CLT plate sample 
The adhesive used in this paper was phenol-resorcinol-formaldehyde type. The cut hemlock and flattened bamboo were first stacked in the way that is perpendicular to each other, so as to prepare a pressured BCLT plate. The general hot-press temperature was above $15{ }^{\circ} \mathrm{C}$. Vacuum compression usually imposes a maximum vacuum pressure of only $0.1 \mathrm{MPa}$. According to this process, three different combinations of BCLT boards were made: bamboo-wood-bamboo sample (BWBCLT), wood-bamboo-wood sample (WBWCLT), and composite bamboo-wood-bamboo sample (CBWBCLT). The bamboo in CBWBCLT is made up of three layers of bamboo. Then, each BCLT plate was cut into BCLT samples. Figure 8 shows the BCLT sample already cut.

\section{Specimens Bending Experiment}

As shown in Fig. 9, four-point bending experiments were conducted on BCLT samples. Load-displacement data were collected for the BCLT plates, and the bending modulus and static bending strength of composite materials were calculated.

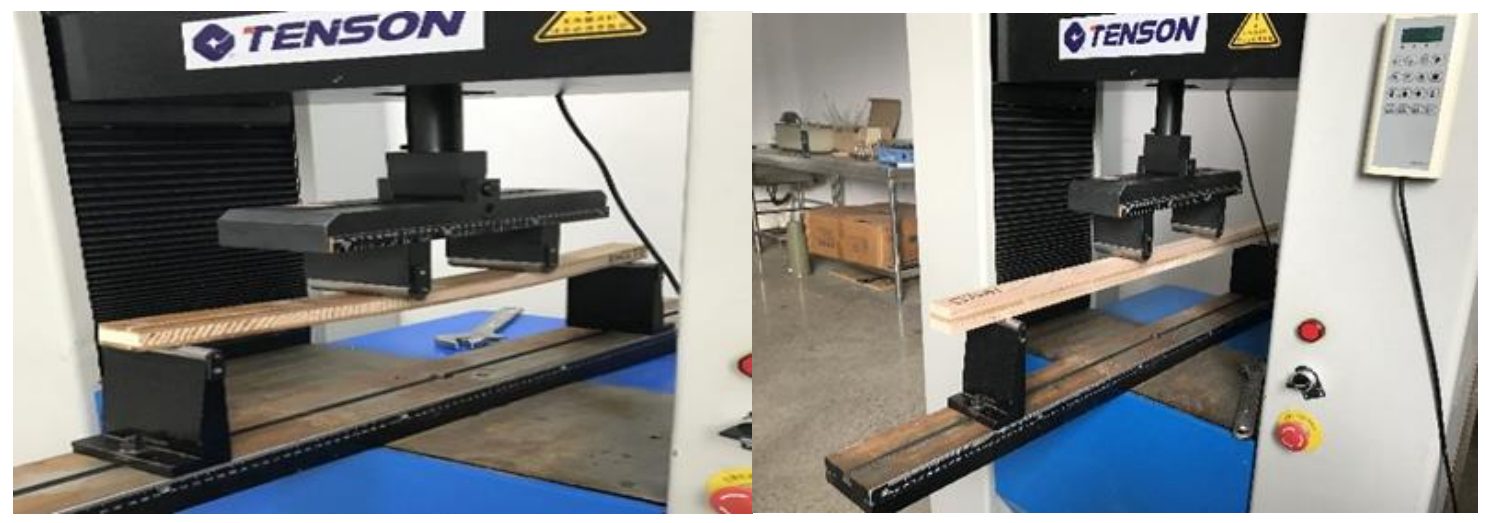

Fig. 9. Samples bending test

\section{Numerical Simulation}

As a composite material, the overall mechanical properties of BCLT plate cannot be analyzed directly by NIR spectral data at present. Therefore, this paper introduces the finite element method. It analyzes the problem into several small finite elements (Marmier et al. 2018) and finds the approximate solution of each finite element. Finally, an approximate solution is obtained for the whole problem. As an efficient and accurate simulation analysis method, finite element analysis is very suitable for the analysis of the overall mechanical properties of CLT.

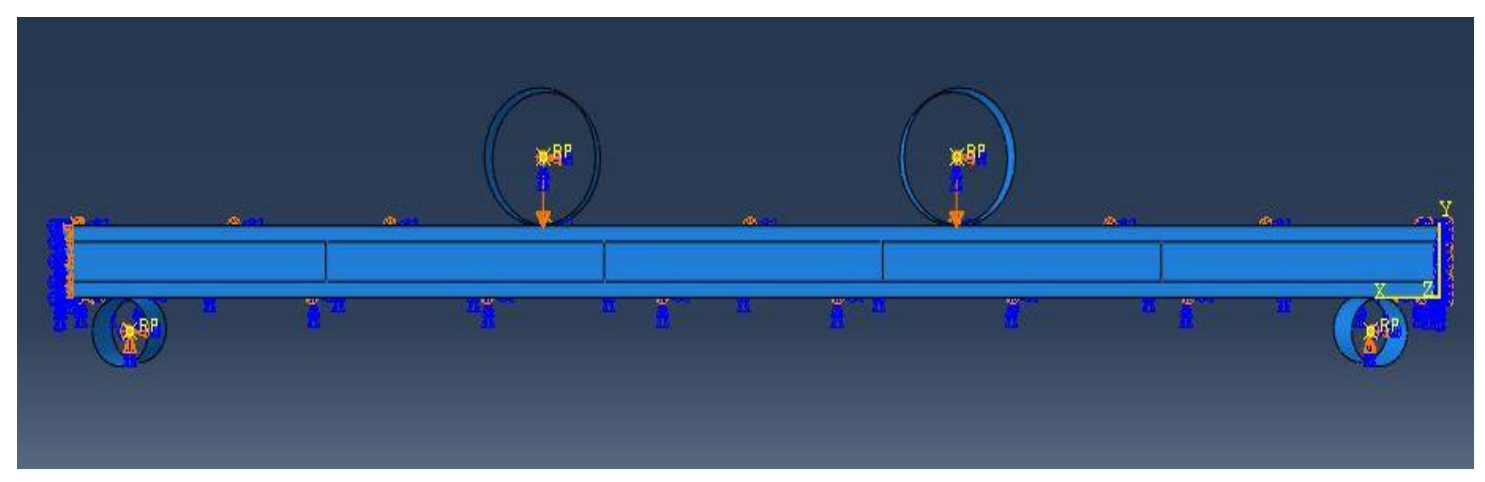

Fig. 10. CLT simulation model 
ANSYS parametric design language (APDL) was used to build the finite element model. The unit type solid185 unit was selected in ANSYS analysis software. According to the NIR spectrum prediction model, the parameters were set for the finite element model. As shown in Fig. 10, using the boundary conditions, the two fulcrum points were constrained under the model sufficiently and pressure was applied at the above two loading points. As shown in Fig. 11, static analysis is sufficient to achieve real simulation.

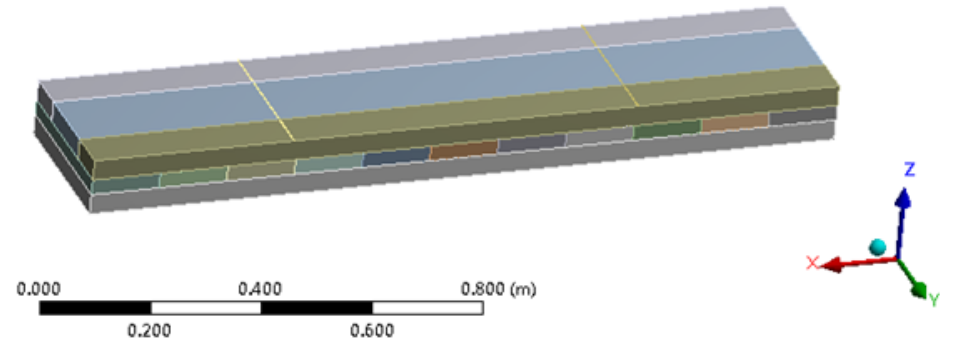

Fig. 11. FE bending numerical model

\section{RESULTS AND DISCUSSION}

\section{NIR Spectrum Data Analysis and Prediction}

Figure 12 shows the wavelength and absorbance curves at different points of the same plate before and after the smoothing pretreatment. It can be seen from the comparison of the two figures that the spectral contour and absorption peak became clearer after treatment.
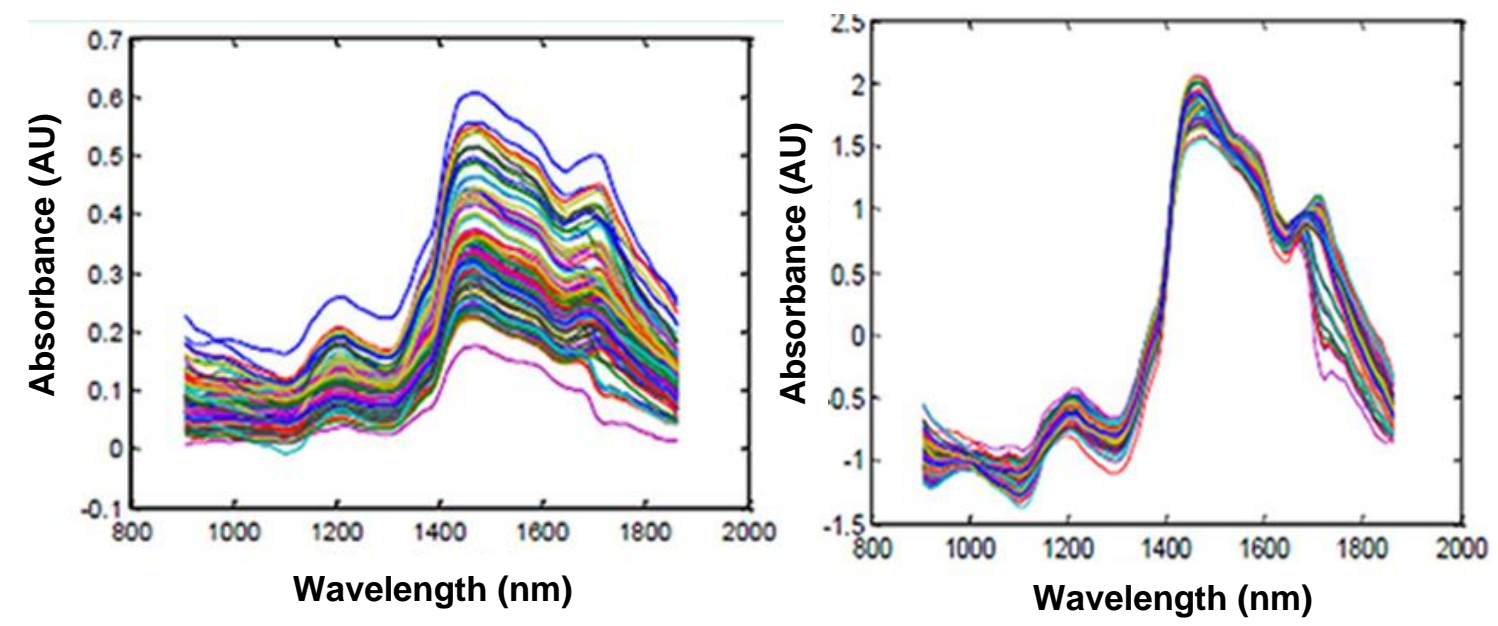

Fig. 12. Comparison of before and after numerical analysis software fitting

Figures 13 and 14 are the wavelength-absorbance curves of WBWCLT and BWBCLT plates. The smoothed curves exhibit a good denoising effect, clear spectral resolution and more obvious spectral contour. The modified model correlation coefficient, cross validation standard deviation (SECV), validation correlation coefficient, and prediction standard deviation (SEP) of the mechanical properties of BCLT were consistent with the expected values. As shown in Tables 1 and 2, SECV is used to correct root mean square error and evaluate the quality of the collected data used to establish the model. Accordingly, $R_{\mathrm{c}}$ and SECV are used as correction indexes. SEP is the prediction root mean 
square error, which is used to evaluate the prediction ability of the established model. It focuses on the prediction ability of the test samples, so that $R_{\mathrm{p}}$ and SEP are used as the adaptability evaluation indexes.

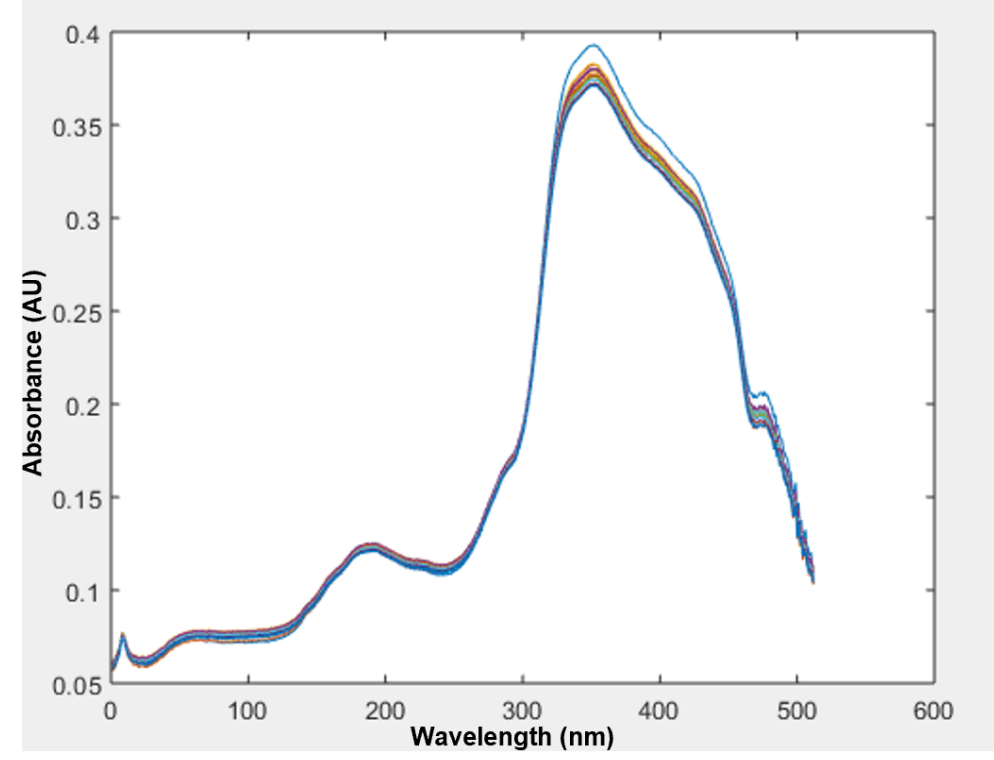

Fig. 13. WBWCLT wavelength-absorbance curve

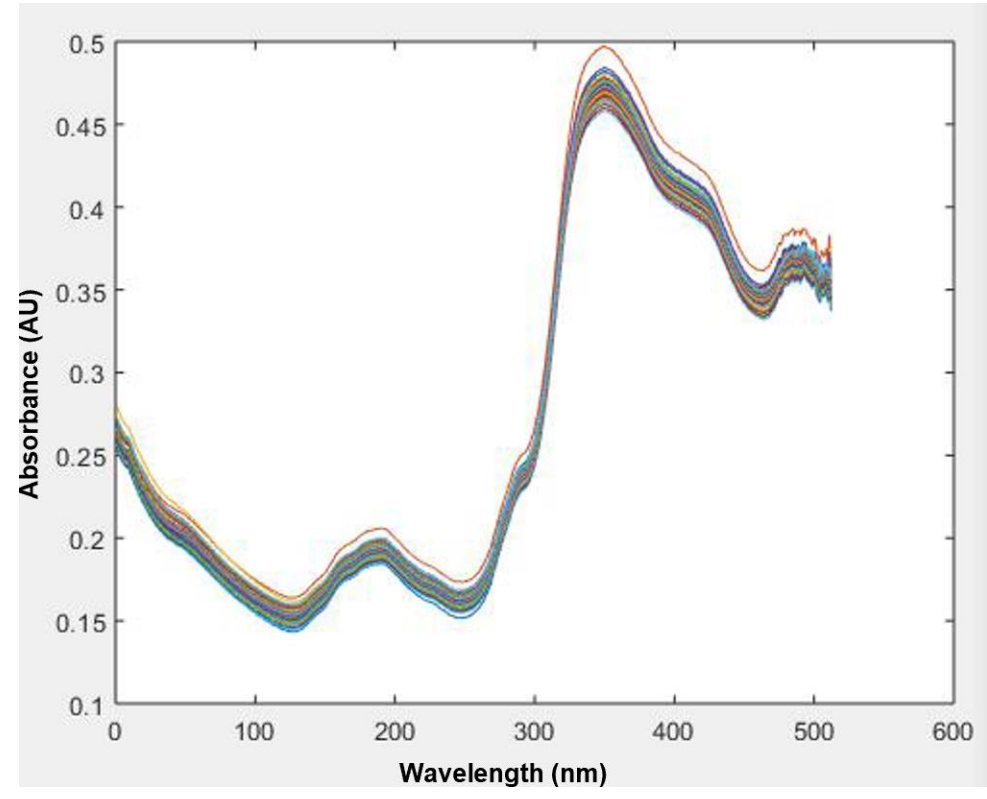

Fig. 14. BWBCLT wavelength-absorbance curve

Table 1. PLS Function Fitting Results (WBWCLT)

\begin{tabular}{|c|c|c|c|}
\hline$R_{\mathrm{c}}$ & SECV & $R_{\mathrm{p}}$ & SEP \\
\hline 0.8962 & 5.1309 & 0.8508 & 5.3370 \\
\hline 0.8845 & 5.2767 & 0.8460 & 5.4911 \\
\hline 0.8931 & 5.1542 & 0.8493 & 5.3507 \\
\hline 0.8745 & 5.4521 & 0.8280 & 5.6131 \\
\hline
\end{tabular}


Table 2. PLS Function Fitting Results (BWBCLT)

\begin{tabular}{|c|c|c|c|}
\hline$R_{\mathrm{c}}$ & SECV & $R_{\mathrm{p}}$ & SEP \\
\hline 0.8539 & 5.7760 & 0.8043 & 5.9104 \\
\hline 0.8357 & 5.9347 & 0.7812 & 6.1047 \\
\hline 0.8468 & 5.8170 & 0.7989 & 6.0712 \\
\hline 0.8610 & 5.6778 & 0.8183 & 5.8990 \\
\hline
\end{tabular}

The model was validated through the prediction set, and the predictive power of the model was tested. Data for the MOR, MOE, and other data were substituted into the NIR prediction model for analysis and prediction. The correlation coefficients $R_{\mathrm{c}}$ for density, MOR, and MOE prediction model were $0.88,0.88$, and 0.85 , respectively. As shown in Table 3, by using NIR, it was possible to predict the physical and mechanical properties of BCLT quickly and nondestructively. The results show that after the pretreatment of the original spectrum, the NIR model based on the optimal modeling spectrum has good prediction results.

Table 3. PLS Function Fitting Results (Total)

\begin{tabular}{|c|c|c|c|}
\hline$R_{\mathrm{c}}$ & SECV & $R_{\mathrm{p}}$ & SEP \\
\hline 0.8831 & 5.1471 & 0.8466 & 5.4331 \\
\hline 0.8810 & 5.1357 & 0.8409 & 5.4580 \\
\hline 0.8538 & 5.3869 & 0.8180 & 5.5818 \\
\hline
\end{tabular}

\section{Rolling Shear Test Results}

BCLT samples were tested by rolling shear on a universal testing machine. The experimental results are shown in Fig. 15. The results showed that the hemlock layer had undergone shear failure, and the bamboo pieces were basically intact. Because bamboo has better bending resistance than hemlock, it only breaks under heavy loads, its shrinkage rate is small, but elasticity and toughness are great, tensile strength and compressive strength are 2.5 times and 1.5 times of Chinese fir, respectively. WBWCLT exhibited the lowest MOR and MOE. BWBCLT showed moderate MOR and MOE. CBWBCLT had the best shear data. Because the outer layer of three-layer bamboo has good bending resistance, it can greatly alleviate the poor bending resistance of hemlock core. The load-displacement curve was obtained from the four-point bending test, and the curve image is shown in Fig. 16. CBWBCLT has better compressive performance than BWBCLT and WBWCLT in terms of load-displacement curve and failure load (F), as shown in Fig. 17. 

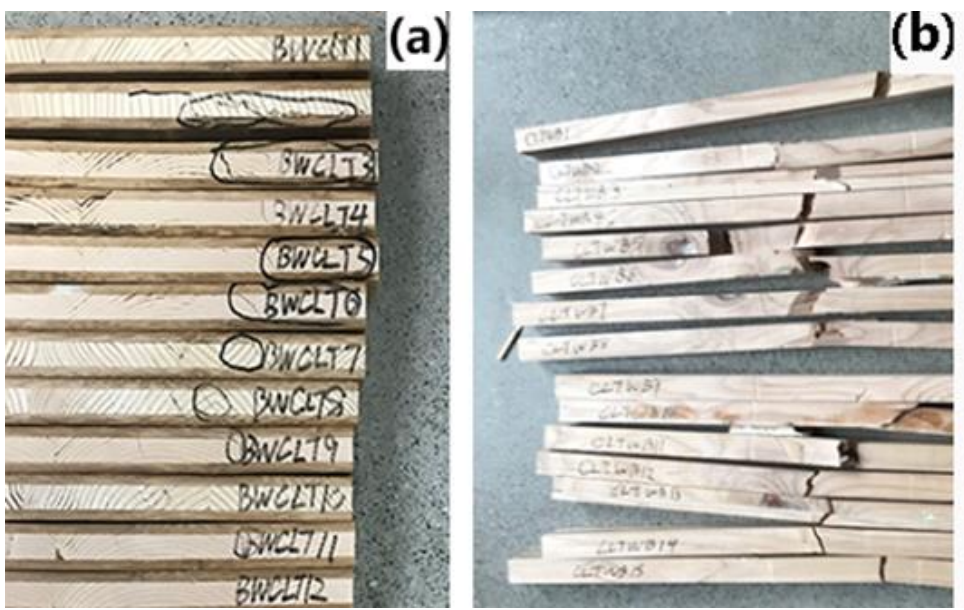

Fig. 15. Damage of actual bending test: (a) BWB damage, (b) WBW damage, and (c) CBWB damage

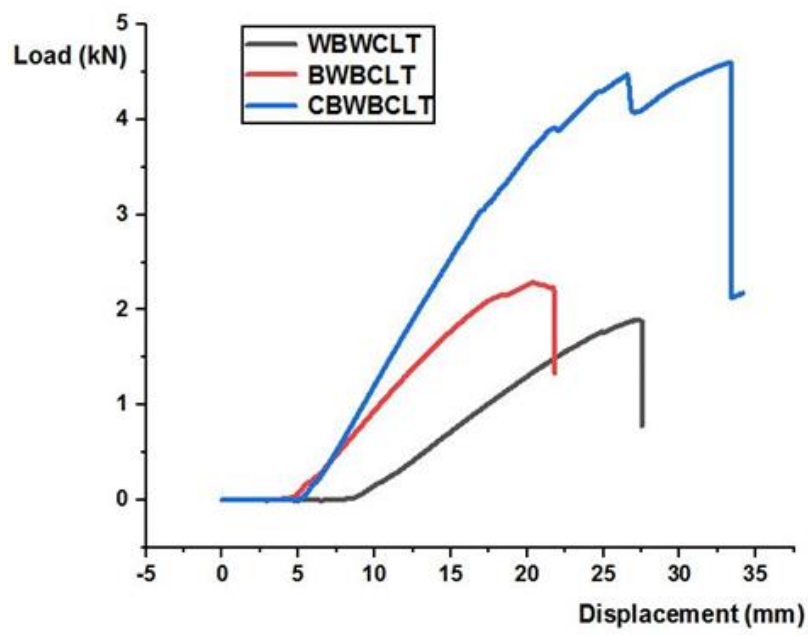

Fig. 16. CLT bending test results

Table 4 shows the comprehensive data of BCLT specimens including MOR, MOE and $\mathrm{F}$, and the variation trend of the three data sequences was $\mathrm{WBW}<\mathrm{BWB}<\mathrm{CBWB}$.

Table 4. MOR and MOE of BCLT Specimens

\begin{tabular}{|c|c|c|c|c|c|c|c|c|c|}
\hline \multirow{3}{*}{ Group } & \multicolumn{3}{|c|}{ MOE } & \multicolumn{3}{c|}{ MOR } & \multicolumn{3}{c|}{$F$} \\
\cline { 2 - 10 } & $\begin{array}{c}\mathrm{AV} \\
(\mathrm{GPa})\end{array}$ & $\begin{array}{c}\mathrm{SD} \\
(\mathrm{GPa})\end{array}$ & $\begin{array}{c}\mathrm{CV} \\
(\%)\end{array}$ & $\begin{array}{c}\text { AV } \\
(\mathrm{MPa})\end{array}$ & $\begin{array}{c}\text { SD } \\
(\mathrm{MPa})\end{array}$ & $\begin{array}{c}\mathrm{CV} \\
(\%)\end{array}$ & $\begin{array}{c}\text { AV } \\
(\mathrm{kN})\end{array}$ & $\begin{array}{c}\text { SD } \\
(\mathrm{kN})\end{array}$ & $\begin{array}{c}\mathrm{CV} \\
(\%)\end{array}$ \\
\hline WBW & 5.720 & 0.532 & 9.31 & 31.58 & 5.439 & 17.22 & 2.069 & 0.437 & 21.16 \\
\hline BWB & 9.472 & 0.744 & 7.85 & 41.91 & 4.144 & 9.89 & 2.235 & 0.221 & 9.89 \\
\hline CBWB & 13.47 & 0.858 & 6.37 & 48.53 & 1.905 & 3.92 & 4.530 & 0.178 & 3.93 \\
\hline
\end{tabular}

Note: AV is Average, SD is standard deviation, and CV is coefficient of variation 

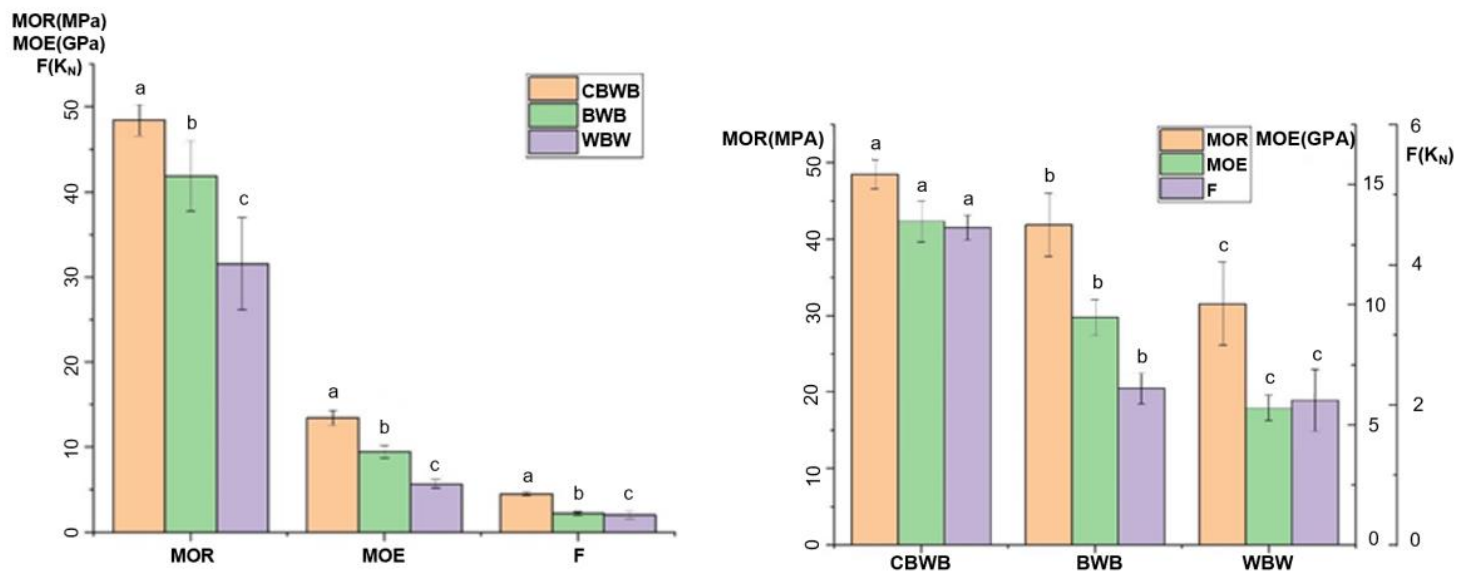

Fig. 17. Error diagram of BCLT

The total deformation cloud map was obtained from finite element analysis. As shown in Figs. 18 and 19, comparing the MOE and rolling shear test data, as shown in Table 5. The results show that NIR was able to predict the mechanical properties of the material nondestructively. Combined with FE analysis of simulation software, CLT orthogonal combination method and material selection, it is feasible to simulate the mechanical strength of bending, compression and rolling shear. The error was within tolerance.
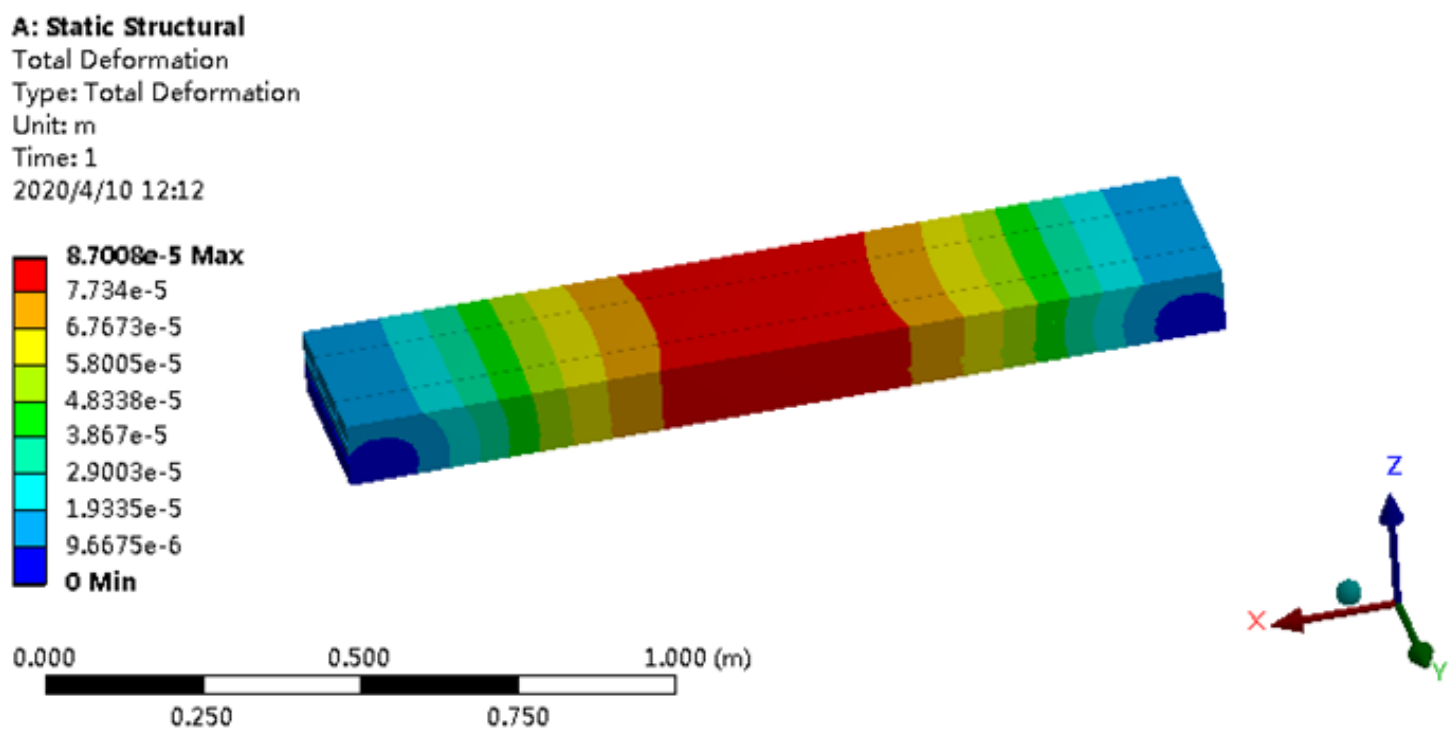

Fig. 18. Total Deformation nephogram 


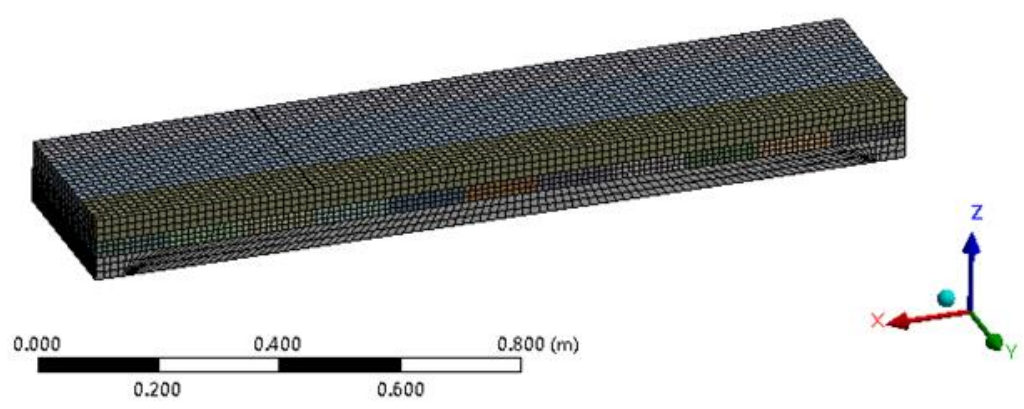

Fig. 19. Mesh of finite element model

Table 5. MOE of Practical Experiment and Numerical Simulation

\begin{tabular}{|c|c|c|c|}
\hline Group & MOE (MPa) & Simulated MOE (MPa) & Error (\%) \\
\hline WBW1 & 5796 & 5849 & 0.9 \\
\hline WBW2 & 6755 & 7092 & 4.75 \\
\hline BWB1 & 8777 & 8513 & 3.01 \\
\hline BWB2 & 8283 & 7457 & 9.97 \\
\hline CBWB1 & 11735 & 12433 & 5.61 \\
\hline CBWB2 & 11439 & 10410 & 9.00 \\
\hline CBWB3 & 11686 & 12620 & 7.40 \\
\hline
\end{tabular}

The NIR spectroscopy prediction method combined with the simulation software analysis method was able to quickly and non-destructively detect the physical and mechanical properties of the materials and determine the most reasonable structural design and raw material collocation of orthogonally stratified building blocks, which greatly saved time and materials.

\section{CONCLUSIONS}

1. The mechanical properties of a single plate were analyzed rapidly and nondestructively by near infrared spectroscopy. After preprocessing the original spectra, the near infrared prediction model established on the optimal modeling spectrum interval obtained better prediction results. The coefficients of determination of the density, MOR and MOE prediction models were $0.88,0.88$, and 0.85 , respectively.

2. The main test methods for MOR and MOE of timber acquisition include four-point bending test methods of different spans, such as the test standard for static mechanical properties of converted timber for structural use (ASTM D198), and the in-plane shear plate test method, such as the test standard for rolling shear properties of wood composite slab for structural use (ASTM D2718). The four-point bending test methods of different spans were used for the shear test in this paper. The shear test showed that CBWBCLT had the best shear performance. Because the outer layer of three-layer bamboo had good bending resistance, it can greatly alleviate the low bending resistance of hemlock core. The thickness and orthogonal combination of CLT affect the roll shear resistance of CLT plate. However, compared with WBWCLT, the use of 
BWBCLT is more economical considering the strength, resources, and growth cycle of the actual materials.

3. The finite element analysis method was adopted to combine the mechanical prediction model of a single plate. A finite element analysis model was established, and the predicted results were compared with the results of mechanical experiments. For the three BCLT plates mentioned in the paper, the prediction error of the finite element model was $4.75 \%, 9.97 \%$, and $5.61 \%$, respectively. Thus, the error was less than $10 \%$. The results show that the numerical simulation of bending test with finite element software is feasible.

\section{ACKNOWLEDGMENTS}

The authors would like to thank for the Program of Innovative Research Group Project of the National Natural Science Foundation of China [grant number 31700643], and the Heilongjiang Provincial Postdoctoral Science Foundation [grant number LBHQ18006].

\section{REFERENCES CITED}

Amusant, N., Beauchène, J., Digeon, A., and Chaix, G. (2016). "Essential oil yield in rosewood (Aniba rosaeodora Ducke): Initial application of rapid prediction by near infrared spectroscopy based on wood spectra," Journal of Near Infrared Spectroscopy 24(6), 507-515. DOI: 10.1255/jnirs.1241

Atienza, A. H., Gutlay, H., Rodrigo, P. V., and Tamayo, P. (2020). "Steam integrated flattening machine for bamboo culms," IOP Conference Series. Materials Science and Engineering, Vol. 739, article no. 12027. DOI: 10.1088/1757899X/739/1/012027

Babiak, M., Gaff, M., Sikora, A., and Hysek, Š. (2018). "Modulus of elasticity in threeand four-point bending of wood," Composite Structures 204, 454-465. DOI: 10.1016/j.compstruct.2018.07.113

Bellini, A., Benedetti, L., Pozza, L., and Mazzotti, C. (2020). "Experimental characterization of monotonic and cyclic behavior of steel-to-CLT nailed joints strengthened with composite plies," Construction and Building Materials 256, article no. 119460. DOI: 10.1016/j.conbuildmat.2020.119460

Cao, J.-X., Xiong, H.-B., Wang, Z.-F., and Chen, J.-W. (2020). “Experimental investigation and numerical analysis for concrete-CLT connections," Construction and Building Materials 236, article no. 117533, 2020. DOI: 10.1016/j.conbuildmat.2019.117533

Corpataux, L., Okuda, S., and Kua, H. W. (2020). "Panel and plate properties of crosslaminated timber (CLT) with tropical fast-growing timber species in compliance with Eurocode 5," Construction and Building Materials 261, article no. 119672. DOI: 10.1016/j.conbuildmat.2020.119672

Gao, Y., Wu, Y.-X., Zhu, X.-D., Zhu, L., Yu, Z.-M., and Wu, Y. (2015). "Numerical analysis of the bending properties of Cathay poplar glulam," Materials 8(10), 70597073. DOI: $10.3390 / \mathrm{ma} 8105362$ 
He, M.-J., Sun, X.-F., and Li, Z. (2018). "Bending and compressive properties of crosslaminated timber (CLT) panels made from Canadian hemlock," Construction and Building Materials 185, 175-183. DOI: 10.1016/j.conbuildmat.2018.07.072

Hong, C.-K., Li, H.-T., Lorenzo, R., Wu, G., Corbi, I., Crobi, O., Xiong, Z.-H., Yang, D., and Zhang, H.-Z. (2019). "Review on connections for original bamboo structures," Journal of Renewable Materials 7(8), 713-730. DOI: 10.32604/jrm.2019.07647

Huang, Z.-J., Sun, Y.-M., and Musso, F. (2017). "Assessment of bamboo application in building envelope by comparison with reference timber," Construction \& Building Materials 156, 844-860. DOI: 10.1016/j.conbuildmat.2017.09.026

Jiang, Z.-H., Huang, A.-M., and Wang, B. (2006). "Near infrared spectral information of different sections of wood and rapid density prediction," Spectroscopy and Spectral Analysis 26(6), 1034-1037.

Li, Y.-X., Zhang, H.-F., Zhang, Y.-C., Zhang, H.-J., and Li, P. (2010). "Prediction model of larch wood density based on near infrared technology," Journal of Northeast Forestry University 38(009), 27-30.

Marmier, A., Biesheuvel, S., Elmalik, M., Kirke, A., Langhof, M., Paiva, J. P., Toudup, J., and Evens, K. E. (2018). "Evidence of negative Poisson's ratio in wood from finite element analysis and off-axis compression experiments," Materials Letters 210, 255257. DOI: 10.1016/j.matlet.2017.09.026

Mo, J.-Q., Zhang, W.-B., Fu, X.-H., and Lu, W. (2020). "Near infrared spectroscopy to evaluate change in color and chemical composition in heat-treated bamboo," Journal of Near Infrared Spectroscopy, article no. 96703352093600, 2020. DOI: 10.1177/0967033520936000

Mohammad, M., Blass, H., Salenikovich, A., Ringhofer, A., Line, P., Rammer, D., Smith, T., and Li, M.-H. (2018). "Design approaches for CLT connections," Wood and Fiber Science 50, 27-47. DOI: 10.22382/wfs-2018-038

Pang, S.-J., and Jeong, G. Y. (2019). "Effects of combinations of lamina grade and thickness, and span-to-depth ratios on bending properties of cross-laminated timber (CLT) floor," Construction and Building Materials 222, 142-151. DOI: 10.1016/j.conbuildmat.2019.06.012

Setiyowati, E., and Mappaturi, A. B. (2020). "Comparison between chemical and natural treatments for bamboo as building material towards sustainable construction method," IOP Conference Series. Earth and Environmental Science 456, article no. 12043. DOI: 10.1088/1755-1315/456/1/012043

Sharma, G., Gatóo, A., Bock, M., and Ramage, M. (2015). "Engineered bamboo for structural applications," Construction \& Building Materials 81, 66-73. DOI: 10.1016/j.conbuildmat.2015.01.077

Sun, X.-F., He, M.-J., and Li, Z. (2020). "Novel engineered wood and bamboo composites for structural applications: State-of-art of manufacturing technology and mechanical performance evaluation," Construction and Building Materials 249, article no. 118751. DOI: 10.1016/j.conbuildmat.2020.118751

Tiryaki, S., and Hamzaçebi, C. (2014). "Predicting modulus of rupture (MOR) and modulus of elasticity (MOE) of heat treated woods by artificial neural networks," Measurement 49, 266-274. DOI: 10.1016/j.measurement.2013.12.004

Yang, Z., Li, K., Zhang, M.-M., Xin, D.-L., and Zhang, J.-H. (2016). "Rapid determination of chemical composition and classification of bamboo fractions using visible-near infrared spectroscopy coupled with multivariate data analysis," Biotechnology for Biofuels 9(35), article no. 35. DOI: 10.1186/s13068-016-0443-z 
Yu, F.-L., Zhao, N., Wu, Z.-S., Huang, M., Wang, D., Zhang, Y.-B., Hu, X., Chen, X.-L., Huang, L.-Q., and Pang, Y.-X. (2017). "NIR rapid assessments of Blumea balsamifera (Ai-na-xiang) in China," Molecules 22(10), 1730. DOI: 10.3390/molecules22101730

Yu, S.-S., Chu, S.-W., Wang, C.-M., Cahng, Y.-K., and Chang, T.-C. (2018). "Two improved k-means algorithms," Applied Soft Computing 68, 747-755. DOI: 10.1016/j.asoc.2017.08.032

Article submitted: February 24, 2020; Peer review completed: April 26, 2020; Revised version received: March 12, 2021; Revised version accepted: March 18, 2021; Published: March 23, 2021.

DOI: 10.15376/biores.16.2.3437-3453 